\title{
RENEWABLES EXPANSION IN NORTHEAST ASIAN POWER GRID
}

\author{
Sergei Podkovalnikov ${ }^{1, *}$, Lyudmila Chudinova ${ }^{1}$ \\ ${ }^{1}$ Melentiev Energy Systems Institute of Siberian Branch of the Russian Academy of Sciences, Electric Power Systems Department, \\ 664033, 130, Lermontova Str., Irkutsk, Russia
}

\begin{abstract}
The paper considers effectiveness of a penetration of renewables into potential Northeast Asia power system interconnection. Renewables are currently in the mainstream of expansion of energy sector in the world and in Northeast Asia, particularly. Formation of NEA power interconnection will increase utilization of variable and poorly predictable renewable generation. Economic incentive for penetration of renewables, like $\mathrm{CO}_{2}$ emission tax, is studied. The study revealed that quite significant tax is needed to be imposed to induce non-fossil fuel generation capacities, including renewable ones, to be added to power systems.
\end{abstract}

\section{Introduction}

Electric power integration with the creation of interstate electric ties (ISETs) and large power grids, including the interstate ones (ISPGs), as well as large-scale use of renewable energy sources (RES) are among the dominant trends in the global power sector. Northeast Asia (NEA) is also on the way of creating ISPGs. A process of active penetration of renewable energy in the national power system of China, the Republic of Korea (ROK), Japan is currently taking place. Further largescale development of RES in these countries and in Mongolia, Russia is possible under conditions of the ISPG creation in the region.

The process of electric power integration in NEA is at an early stage. It is necessary to study scenarios of the future formation of ISETs and ISPG in the region, particularly with large-scale penetration of RES. This meets the requirements of the Paris agreement on the constraint of emissions of carbon dioxide $\left(\mathrm{CO}_{2}\right)$ and other greenhouse gases [1], ratified by Russia in 2019 [2]. Only a few studies of this kind were performed so far. The study was conducted on the "environmental" scenario for the expansion of the ISPG in NEA, taking into account the tax on $\mathrm{CO}_{2}$ emissions [3]. At the same time, RES generation was not optimized, but was set according to national development strategies. The study of an "idealized" ISPG in the NEA region based entirely on RES was performed in [4]. Meanwhile, Russia, which has a significant potential for renewable energy, was not considered in the study.

In the presented paper, we have studied the prospects for expansion of RES in the framework of a potential ISPG in NEA with optimization of their capacity and power along with the capacity and power of traditional power plants (thermal, nuclear, hydraulic). At the same time, a tax on $\mathrm{CO}_{2}$ emissions was used as a mechanism for stimulating renewable energy sources expansion. The computational tool for the study was a specially improved optimization model of expansion and economic dispatching of electric power systems (EPSs) named ORIRES [5].

The results of the study showed that RES can take a important place in the potential electricity balance of NEA, and the ISPG will contribute to their more complete and effective utilization to cover the joint electric load of consumers in the region.

\section{Fundamentals of research}

\subsection{Assumptions}

This research continues the previous studies of the authors aimed at investigating formation of ISETs and ISPG in Northeast Asian region with deeper consideration given to environmental issues and renewable energies, which is a mainstream of energy and power development in the world and NEA, particularly, as was noted above. It was assumed that solar and wind energies can be intensively developed in China, ROK, Japan, Mongolia (Gobitec project) and tidal energy - in Russia.

$\mathrm{CO}_{2}$ emission tax was used in the study as economic lever for stimulating RES generating facilities (and also other non-carbon generating capacity, like nuclear one) expansion. $\mathrm{CO}_{2}$ emission tax was assumed to be equal to USD 60 per ton as a medium value from the range of values given in [6] for 2040 (see below). Besides, zero $\mathrm{CO}_{2}$ emission tax level was also considered as a ground level for comparison. 
The target year for the study (for which all calculations are performed) was assumed to be 2040, as the last year of the time period considered in the study.

The ISETs in the region were assumed to be installed as HVDC $\pm 800 \mathrm{kV}$ transmission lines and submarine cables. The cables are needed to cross the sea straits (between mainland and Japan, mainland and Sakhalin). This rated voltage has already reached for overhead lines, and is supposed to be reached for submarine cables in the course of the time period considered in the study (from nowadays up to 2040).

\subsection{Basic methodology}

General methodology for the study involves comparison of base case scenario (with no ISETs) with scenario of ISPG formation and estimation of its benefits as differences between main economic characteristics (like total cost, fuel cost, required generating capacities, investments, etc.) of these scenarios. The methodology has been described in $[7,8]$ and is not presented here.

The above scenarios were detailed to take into account $\mathrm{CO}_{2}$ tax emission. Pairs of scenarios including Base case one and scenario of NEA ISPG formation were presented for assumed levels of $\mathrm{CO}_{2}$ tax, including zero $\mathrm{CO}_{2}$ emission tax, and level of tax in the amount of
USD 60 per ton of carbon dioxide emission accordingly. These scenarios were optimised by using mathematical model for expansion and dispatching of electric power systems ORIRES [5,9].

The model was modified for the study. Particularly, optimisation of RES capacity expansion is fulfilled in the modified model that was not done earlier. Power generation of RES was set by daily generation profiles, based on available statistics on solar and wind activities in the considered regions. Amount of RES power generation depends proportionally on the RES capacity and calculated by the model according to optimised RES capacity.

\subsection{Data}

Interstate power grid in NEA is presented in the study as 10-node diagram (Fig.1). Russia and China are presented by three interconnected nodes, the rest countries are presented by one node each.

It should be noted that for the base case scenario ISETs are absent, and the diagram given in Fig. 1 breaks apart into separate national EPSs presented by single nodes or several interconnected nodes (as in the case of China and Russia).

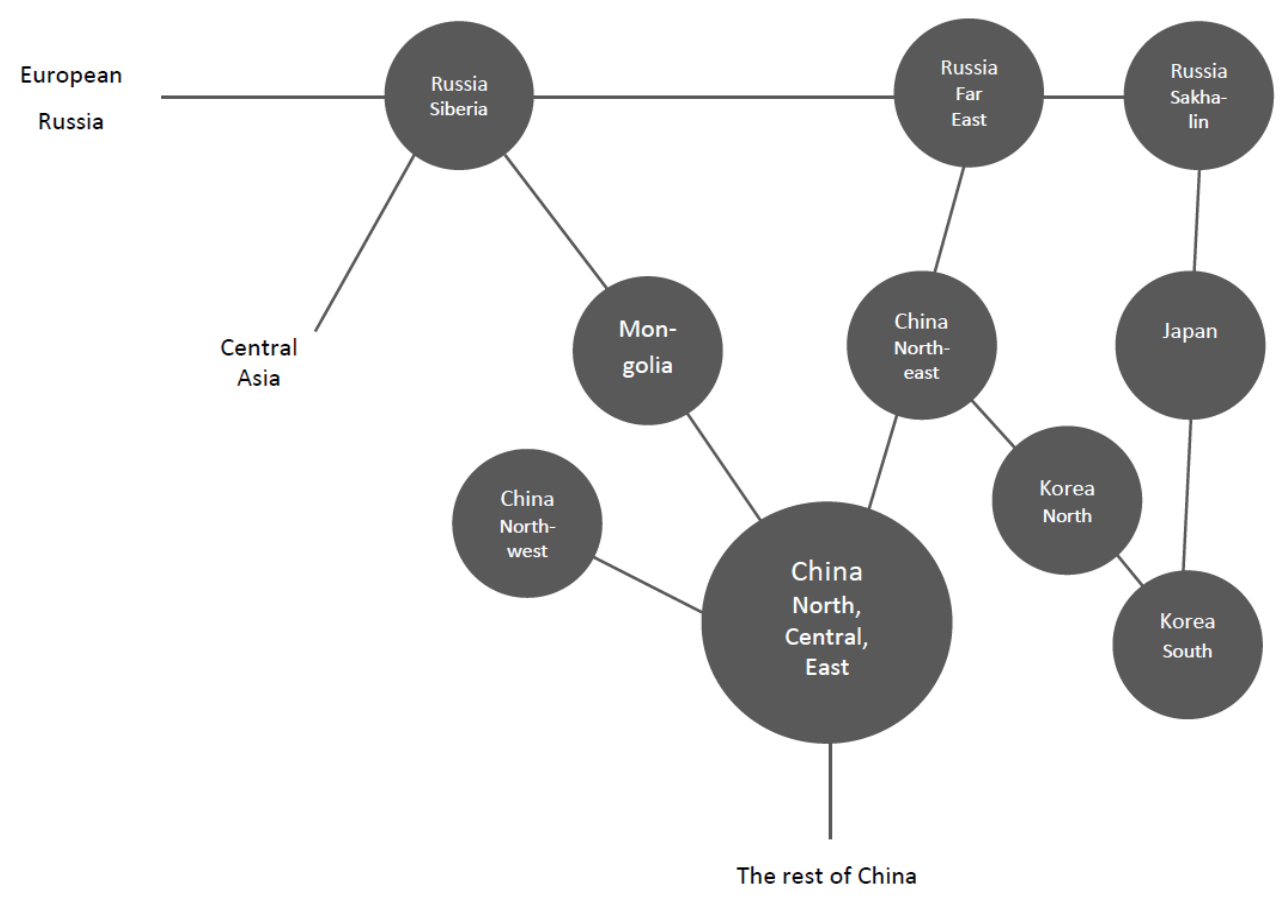

Fig. 1. Diagram of the interstate power grid in NEA.

Major economic and technical input data for the research was taken from reports and studies made by international, governmental and scientific organizations of the considered Northeast Asian countries [6,9-12, etc.]. The data was collected, processed and presented by authors in research papers $[3,7,9]$ and that is why is not given here. Renewables development was not optimized in these researches and, therefore, their input data was not presented there.
Investment cost of wind and solar capacity by NEA country is given in Table 1. Annual fixed operation and maintenance cost of RES was assumed to be $2-2.5 \%$ of their investment cost.

Prospective electricity demand in the countries was assumed to grow according to business-as-usual national scenarios [11]. 
Table 1. Specific investment cost in renewables, USD $/ \mathrm{kW}$.

\begin{tabular}{|l|c|c|}
\hline Country & Wind & Solar \\
\hline China & 1200 & 930 \\
\hline DPRK & 1600 & 1500 \\
\hline Japan & 3000 & 2500 \\
\hline RoK & 2500 & 1800 \\
\hline Monglia & 1250 & 950 \\
\hline
\end{tabular}

\section{Results and discussions}

Presented in the Table 2 are integration system benefits obtained due to creation of interstate power grid in NEA. As can be seen, high positive benefits take place under different assumed levels of carbon dioxide emissions tax. Resulting economic benefit and investment benefit decrease substantially with the introduction of $\mathrm{CO}_{2}$ emission tax, because capital intensive RES capacity is added and increases its generating capacity and share in the total installed capacity of NEA ISPG. Cost of ISETs including investment cost decreases with the introduction of $\mathrm{CO}_{2}$ tax. This means that electric ties expansion and accordingly intensity of power exchange declines when the tax is in place. This point will be considered further. On the contrary, fuel benefit grows when the tax is imposed. This is because carbon dioxide tax is translated into fossil fuel cost in the model.

Table 3 gives detailed data on capacity additions by type of power plant and country for scenarios of absence and presence of ISPG and $\mathrm{CO}_{2}$ emission tax. This data confirms values of capacity benefit given in Table 2 (as difference between total capacity addition for the cases of no interconnection and presence of interconnection), and additionally shows contribution of different types of power plants and countries into capacity benefit.

Data from the Table 3 shows substantial effect of $\mathrm{CO}_{2}$ emission tax introduction on volumes and mix of installed generating capacity of power systems no matter they are separate or interconnected. As it follows from Table 3, $\mathrm{CO}_{2}$ tax stimulates introduction of non-carbon (wind and solar in the amount of 205-214 GW and nuclear - 147-180 GW) and low carbon (gas thermal -

Table 2. Benefits of the interconnection.

\begin{tabular}{|c|c|c|c|c|c|c|c|c|c|}
\hline \multirow{2}{*}{ Components of benefits } & \multicolumn{4}{|c|}{ Economic benefit, \$ Bln/year } & \multicolumn{3}{c|}{ Investment benefit, \$ Bln. } & Capacity \\
\cline { 2 - 10 } & & Power plants & Fuel & ISETs & Total & Power Plants & ISETs & Total & benefit, GW \\
\hline $\begin{array}{c}\text { Carbon dioxide } \\
\text { emission tax, } \\
\$ / \text { ton of } \mathrm{CO}_{2}\end{array}$ & 0 & 19.6 & 4.9 & -4.9 & 19.6 & 109.5 & -39.1 & 70.4 & 58.5 \\
\cline { 2 - 11 } & 8.0 & 7.0 & -4.3 & 10.7 & 48.1 & -34.5 & 13.6 & 54.7 \\
\hline
\end{tabular}

Table 3. Capacity additions by type of power plants and country, no $\mathrm{CO}_{2}$ emission tax/ USD 60 per ton of $\mathrm{CO}_{2}$ emission tax, $\mathrm{GW}$.

\begin{tabular}{|c|c|c|c|c|c|c|c|c|}
\hline Capacity & Hydro & $\begin{array}{l}\begin{array}{l}\text { Pumper } \\
\text { storage }\end{array} \\
\end{array}$ & $\begin{array}{c}\text { Thermal, } \\
\text { coal }\end{array}$ & $\begin{array}{l}\text { Thermal, } \\
\text { gas }\end{array}$ & Nuclear & Wind & Solar & Total \\
\hline \multicolumn{9}{|c|}{ No power system interconnection } \\
\hline Russia & $0 / 0.74$ & & $1.27 / 0$ & $2.23 / 0.2$ & $0 / 3.0$ & & & $3.50 / 3.94$ \\
\hline China & $\begin{array}{l}72.42 / \\
72.17 \\
\end{array}$ & $\begin{array}{l}88.09 / \\
42.41 \\
\end{array}$ & $\begin{array}{l}345.5 / \\
237.6\end{array}$ & & $\begin{array}{l}50.85 / \\
188.25 \\
\end{array}$ & $0 / 91.2$ & $0 / 112.8$ & $556.86 / 744.43$ \\
\hline DPRK & $2.24 / 2.91$ & & $4.24 / 4.04$ & $7.40 / 7.40$ & & $0.23 / 0.23$ & $0.19 / 0$ & $14.30 / 14.58$ \\
\hline Japan & & & $21.80 / 0$ & $19.09 / 38.00$ & $0 / 6.80$ & & & $40.89 / 44.80$ \\
\hline RoK & $0.51 / 0.51$ & $2.00 / 0$ & $9.91 / 0$ & $0.93 / 12.83$ & $\begin{array}{l}19.84 / \\
19.84 \\
\end{array}$ & & & $33.18 / 33.18$ \\
\hline Monglia & $0.26 / 1.13$ & $0.20 / 0.20$ & $2.50 / 1.63$ & & & $0 / 0.15$ & $0 / 1.82$ & $2.96 / 4.93$ \\
\hline Total & $\begin{array}{l}75.42 / \\
77.46 \\
\end{array}$ & $\begin{array}{c}90.29 / \\
42.61 \\
\end{array}$ & $\begin{array}{l}385.21 / \\
243.27 \\
\end{array}$ & $29.65 / 58.43$ & $\begin{array}{l}70.69 / \\
217.89 \\
\end{array}$ & $0.23 / 91.58$ & $0.19 / 114.62$ & $651.68 / 845.86$ \\
\hline \multicolumn{9}{|c|}{ Power system interconnection } \\
\hline Russia & $4.15 / 8.59$ & & $0.24 / 0$ & $0.45 / 1.08$ & $0 / 3.00$ & & & $4.84 / 12.67$ \\
\hline China & $\begin{array}{l}72.42 / \\
72.17 \\
\end{array}$ & $\begin{array}{c}88.09 / \\
6.86 \\
\end{array}$ & $\begin{array}{l}345.5 / \\
243.74\end{array}$ & & $\begin{array}{l}18.31 / \\
188.25\end{array}$ & $0 / 91.2$ & $0 / 112.8$ & $524.32 / 715.02$ \\
\hline DPRK & $2.91 / 2.91$ & & $0.76 / 0$ & $0 / 3.67$ & & & & $3.67 / 6.58$ \\
\hline Japan & & & $21.80 / 0$ & $0 / 19.77$ & $0 / 6.80$ & & & $21.80 / 26.57$ \\
\hline RoK & $0.51 / 0.51$ & $2.00 / 0$ & $9.91 / 0$ & $3.57 / 0$ & $\begin{array}{l}19.84 / \\
19.84 \\
\end{array}$ & & & $35.83 / 20.35$ \\
\hline Monglia & & $0.20 / 0.17$ & $2.50 / 0$ & & & & $0 / 9.86$ & $2.70 / 10.03$ \\
\hline Total & $\begin{array}{l}79.98 / \\
84.18 \\
\end{array}$ & $90.29 / 7.04$ & $\begin{array}{l}380.71 / \\
243.74 \\
\end{array}$ & $4.02 / 24.52$ & $\begin{array}{l}38.15 / \\
217.89\end{array}$ & $0 / 91.20$ & $0 / 122.66$ & $593.15 / 791.22$ \\
\hline
\end{tabular}


20-29 GW) power sources. This causes substantial decrease of coal-fired thermal capacity in the amount of 137-142 GW.

In presence of $\mathrm{CO}_{2}$ emission tax RES expands in China. Additionally, solar panels are brought on line in Mongolia in the case of NEA power interconnection. Without interconnection even though in presence of $\mathrm{CO}_{2}$ tax large capacity of renewables is not introduced in Mongolia because of limited national electricity market. NEA-wide power interconnection opens up opportunities for Mongolian renewables to enter international electricity market and thus induces their large-scale development.

It is needed to note that power system interconnection stimulates additionally introduction of non-carbon power sources (9 GW for RES and $33 \mathrm{GW}$ for nuclear - as difference between high and low values of the given above ranges). Effect of interconnection (in presence of $\mathrm{CO}_{2}$ tax) on pumped storage capacity is dramatic. The capacity decreases six fold in comparison with the case of absence of interconnection (and presence of tax). This is because interconnected power system has extended capability to regulate and adopt stochastic injections and withdrawal of power from RES that decreases needs of power system in power storage facilities.

The share of RES (with $\mathrm{CO}_{2}$ emission tax in place) in total capacity additions is quite high being $25 \%$ in the case of no interconnection and reaching $27 \%$ in the case of interconnection.

The total capacity of power systems no matter they are separate or interconnected increases with large-scale introduction of RES by 194-198 GW. This is because wind and solar facilities are plants with non-firm variable power generation and they need to be reserved by firm power sources.

Figure 2 presents capacity by type of power plants for the case of power interconnection in NEA. As can be seen coal-fired thermal power plants still dominate in the capacity mix being three-four times more that solar or wind capacity. As it follows from the Figure 2, the share of RES in total installed capacity of potential NEA ISPG (with presence of $\mathrm{CO}_{2}$ tax) slightly exceeds $20 \%$.

The share of all non-carbon facilities considering additionally traditional hydro and nuclear in the total capacity is more than twofold and takes $45 \%$. If lowcarbon facilities are considered additionally (particularly, gas-fired power plants) the share of non-carbon and low carbon capacity is over than half of total NEA ISPG capacity, being about $55 \%$. Thus, the share of environmentally dirty coal-fired power plants in NEA ISPG installed capacity is still expected to be quite high reaching $45 \%$ in the target year in spite of taking the measures of environmental protection like $\mathrm{CO}_{2}$ emission tax.

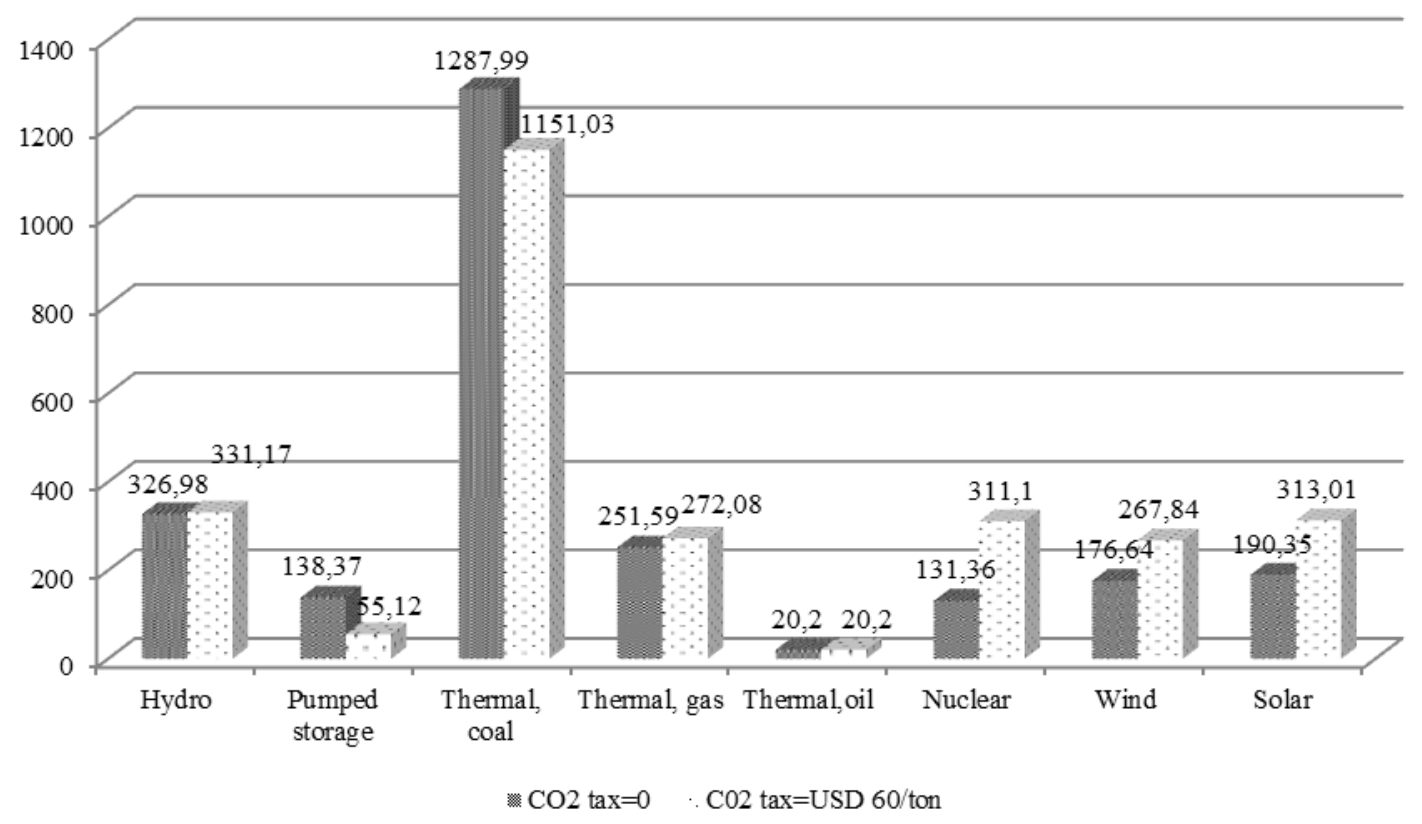

Fig. 2. Installed capacity of NEA power grid for 2040 target year, GW.

Figure 3 presents power generation of potential NEA interconnection and its breakdown by type of power plants. As is seen, RES, having more than $20 \%$ of the total installed capacity (as it follows from the above), takes much smaller share of the total power generation being about $8 \%$. This is due to small number of utilization hours of RES capacity determined by climatic conditions. However, total share of non-carbon and low- carbon power generation is again equal to $55 \%$ of the total generation. This is mainly due to substantial contribution of nuclear capacity having high number of utilization hours typical for this type of power plants. Thus, share of environmentally dirty coal-fired power plants in power generation as well as in installed capacity of NEA ISPG is still expected to be quite high 
reaching $45 \%$ in the target year subject to a $\mathrm{CO}_{2}$ emission tax.

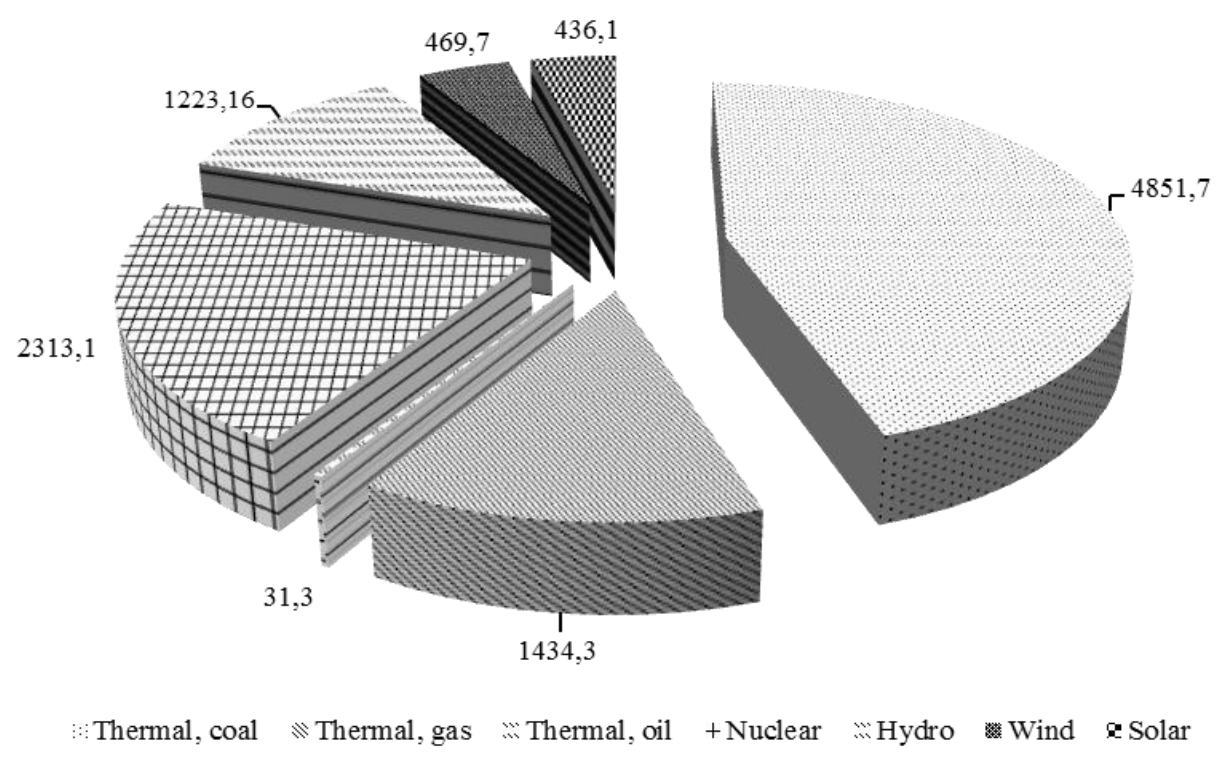

Fig. 3. Power generation of NEA power grid for 2040 target year, $\mathrm{CO}_{2}$ tax $=\mathrm{USD}$ 60/ton, TWh/year.

Optimal transfer capacities of ISETs for scenario of NEA power interconnection depending on presence or absence of $\mathrm{CO}_{2}$ emission tax are given in Table 4. As is seen, presence of the tax suppresses development of interstate transmission infrastructure. This corresponds to given above note that cost in ISETs decreases when $\mathrm{CO}_{2}$ emission tax is in place. Transfer capacities decreases because the need for power exchange reduces in presence of the tax. This is explained further.

Table 4. Transfer capacities of ISETs in presence of NEA ISPG, GW.

\begin{tabular}{|l|c|c|}
\hline ISETs & 0 & USD 60/ton \\
\hline Russia (Siberia)-Mongolia & 14.4 & 12.9 \\
\hline Russia (East)-DPRK & 2.7 & 3.6 \\
\hline $\begin{array}{l}\text { Russia (East)-China } \\
\text { (Northeast) }\end{array}$ & 5 & 5 \\
\hline Russia (East) -Japan & 5 & 5 \\
\hline $\begin{array}{l}\text { Mongolia-China (North- } \\
\text { Central-East) }\end{array}$ & 14.7 & 11.3 \\
\hline China (Northeast)-DPRK & 15 & 15 \\
\hline DPRK-RoK & 15 & 15 \\
\hline RoK-Japan & 15 & 11.1 \\
\hline Total & 86.8 & 78.9 \\
\hline
\end{tabular}

Figure 4 presents amounts of power exchange over ISETs among countries to be participated in NEA ISPG under presence and absence of $\mathrm{CO}_{2}$ emission tax. Total amount of export-import exchanges is quite large -1000 $\mathrm{TWh} /$ year with no $\mathrm{CO}_{2}$ tax and $830 \mathrm{TWh} /$ year with tax equals to USD $60 / \mathrm{t}$ of $\mathrm{CO}_{2}$.

As has already been noted introduction of $\mathrm{CO}_{2}$ emission tax curbs power exchange. Particularly, China substantially decreases its electricity export. This is because of the following reason. China having large fleet of cheap coal-fired power plants in the case of NEA power interconnection and with no $\mathrm{CO}_{2}$ tax can supply power abroad and compete on international electricity market. $\mathrm{CO}_{2}$ tax introduction makes power from Chinese coal-fired power plants more expensive and less competitive on NEA electricity market, and China decreases its power supply abroad. Thus, China decreases its power export by more than $20 \%$ (or by 41 $\mathrm{TWh} /$ year), and overall NEA-wide decrease of export in presence of $\mathrm{CO}_{2}$ tax is $17 \%$ (or $89 \mathrm{TWh} /$ year).

As can be seen from Figure 4, the largest electricity importer is Japan. Countries of Korean Peninsular are both large importers and exporters. This means that they are mostly transient countries, providing corridors to transmit power over their territories to Japan. 


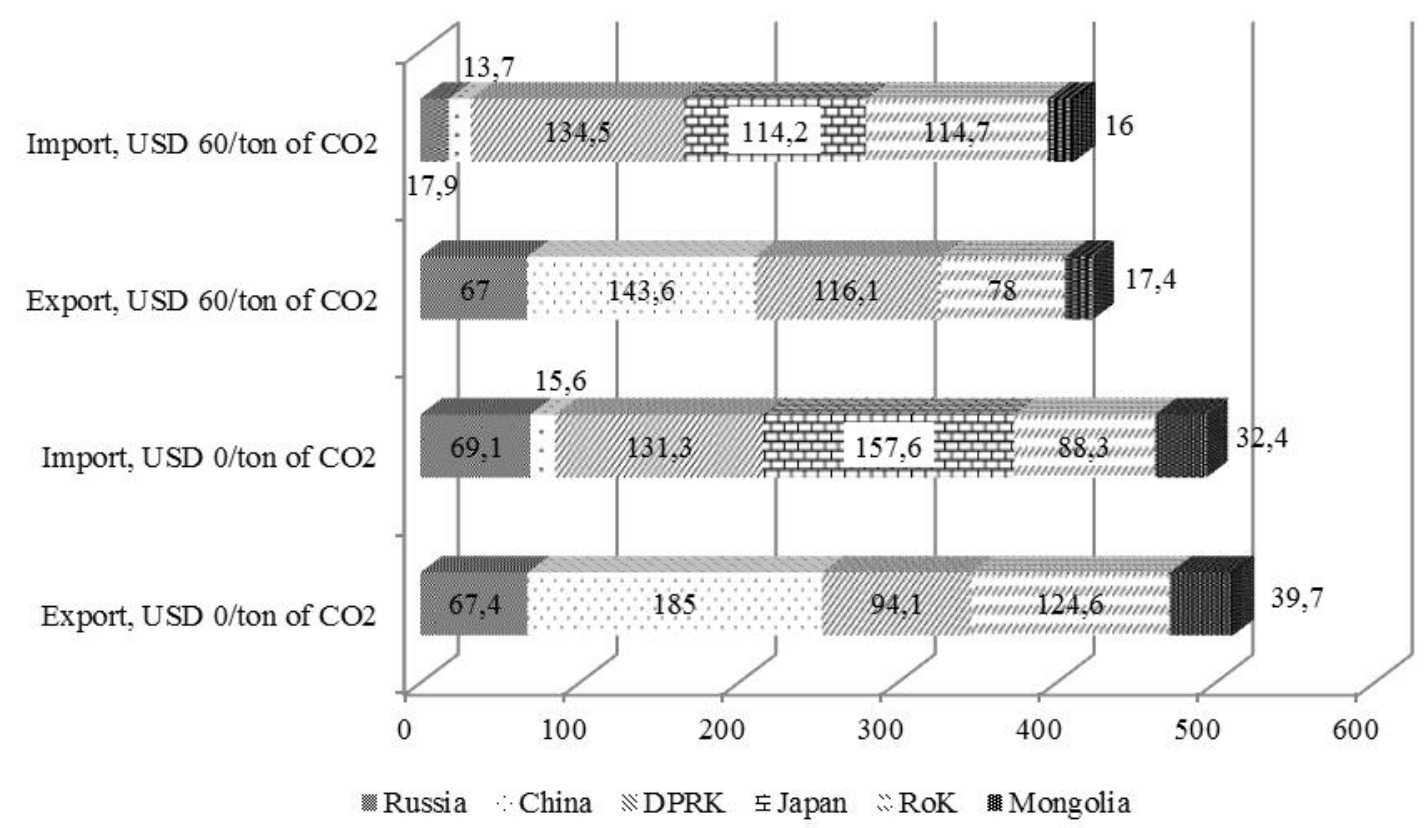

Fig. 4. Expor/import power flows within NEA ISPG, 2040, TWh/year.

\section{Conclusions}

The conducted research has confirmed possibility and economic feasibility for extensive renewable energy integration into potential interstate power system interconnection in Northeast Asia. NEA power system interconnection remains beneficial no matter $\mathrm{CO}_{2}$ emission tax is introduced or not. However system integration benefits as well as transfer capacity of and power exchange over international network infrastructure of NEA power interconnection are reduced when the tax is in place. This is mainly due to decrease of power export from Chinese coal-fired power plants in presence of the tax.

Mid-level $\mathrm{CO}_{2}$ emission tax used in the study induced expansion of renewables and in general noncarbon (nuclear) and low-carbon (gas-fired) generating capacities. Nonetheless, the tax does not allow renewables to take prevailing position in NEA interconnection by the assumed target year. Wind and solar facilities are massively developed in China and in case of NEA power interconnection in Mongolia. Thermal environmentally dirty coal-fired power plants still take important role in NEA interconnection even in presence of $\mathrm{CO}_{2}$ emission tax.

Further research needs to be done to study large-scale renewables expansion in NEA power interconnection at more powerful economic tool inducing such an expansion.

The research was carried out under State Assignment, Project 17.6.2 (reg. no. AAAA-A17117030310447-3) of the Fundamental Research of Siberian Branch of the Russian Academy of Sciences and partly supported by the Russian Foundation of Basic Research, grant no. 18-07-00495-A.

\section{References}

1. Paris Agreement under the United Nations Framework Convention on Climate Change. December 12 (2015)

2. Decree of the Government of the Russian Federation. 1228 (2019)

3. S.V. Podkovalnikov, V.A. Saveliev, L.Yu. Chudinova. Study of systemic energy-economic efficiency of the formation of the interstate power interconnection of North-East Asia. Russian Academy of Sciences Proceedings. Energy, 5 (2015) (in Russian)

4. D. Bogdanov, C. Breyer. North-East Asian Super Grid for $100 \%$ renewable energy supply: Optimal mix of energy technologies for electricity, gas and heat supply options. Energy Conversion and Management, 112 (2016)

5. L.S. Belyaev, L.Yu. Chudinova, S.V. Podkovalnikov, V.A. Saveliev. The effectiveness of interstate electrical ties. Novosibirsk (2008) (in Russian)

6. P. Luckow, E. Stanton, S. Fields et al. Spring 2016 National Carbon Dioxide Price Forecast. Cambridge. Massachusetts (2016) http://www.synapseenergy.com/sites/default/files/2016-Synapse-CO2Price-Forecast-66-008.pdf

7. L.Yu. Chudinova, S.V. Podkovalnikov, I.L. Trofimov. Prospective Cooperation between the Unified Power System of Russia and Asian Supergrid. 2019 International Multi-Conference on Industrial Engineering and Modern Technologies (FarEastCon): proceedings. Vladivostok. Russia (2019) 
8. S.V. Podkovalnikov, L.Yu. Chudinova Methodical Issues and Researches of Russia's Power Systems Expansion within Interstate Power Interconnections. Electricity. Transmission and Distribution. 4 (2020) (in Russian)

9. O.V. Khamisov, S.V. Podkovalnikov. Shadow Price Analysis of Potential Northeast Asia Power System Interconnection. 2018 IEEE PES Asia-Pacific Power and Energy Engineering Conference (APPEEC). IEEE Xplore. Kota Kinabalu. Malaysia (2018)

10. Projected Cost of Generating Electricity. International Energy Agency. Paris (2015)

11. IEEJ Outlook 2019 - Energy Transition and Thorny Path for $3 \mathrm{E}$ Challenges. The Institute of Energy Economics. Japan. Tokyo (2017)

12. P.M. Mishra. A Comparison on Development of Pumped Storage Hydropower in Europe and Asia. The Arctic University of Norway. Narvik. (2017) 